Reference Centre. Women aged 50-52 who had a first call invitation (a first invitation to the national screening programme) in this period, and women aged 50-69 who had a routine recall invitation (after previously having a mammography as part of the screening programme) were analysed. Where ethnicity was not known, multiple imputation was used. First call and routine recall data were analysed separately. Screening uptake in different ethnic groups was assessed using logistic regression, and adjusted for age at invitation, socioeconomic deprivation and screening area. Data for the six individual screening areas were also analysed separately.

Results Data on 159,078 women were included in the first call analysis, and on 496,438 women in the routine recall analysis. Ethnicity information was available for 475,478 (72.5\%) of these women. Compared with White British women, all other ethnic groups were less likely to attend their first call screening invitation. White British women were also most likely to attend for routine recall screening sessions. Some screening areas showed less variation, with women from several ethnic groups having similar screening uptake to White British women.

Conclusion Breast cancer screening attendance varies by ethnic group for both the first invitation and for subsequent invitations after previously being screened, with White British women more likely to attend. Collaboration between areas to find successful practices for engaging with different communities should improve breast cancer screening uptake.

\section{PS33 HEALTH-SEEKING BEHAVIOUR IN THE ERA OF FREE HEALTHCARE IN URBAN SLUMS IN SIERRA LEONE}

doi:10.1136/jech-2012-201753.132

'L Nathaniel-Wurie, 'G Martin, ' $\mathrm{G}$ Cooper, ${ }^{1} \mathrm{G}-\mathrm{L}$ De Bernier, ${ }^{2} \mathrm{~T}$ Ajayi, ${ }^{2} \mathrm{~F}$ Martineau, ${ }^{2} \mathrm{~B}$ Cridford, ${ }^{2} \mathrm{~S}$ Lako. 'Global Health Department School of Medicine and Dentistry, King's College London, London, UK; ${ }^{2}$ Welbodi Partnership, Freetown, Sierra Leone

Background Sierra Leone has child health statistics which are amongst the worst in the world. In April 2010, the Government of Sierra Leone launched a Free Health Care Initiative (FHCI), eliminating user fees in government facilities for children under the age of five, as well as pregnant and lactating women. Data from Ola During Children's Hospital (ODCH), the country's only government-run tertiary paediatric hospital, suggests that the FHCI has increased service utilisation. However, mortality rates remain high and delayed presentation is a major factor contributing to poor outcomes. This study sought to understand health-seeking behaviour in the era of Free Health Care, as a means of addressing barriers to the delivery of timely paediatric care for the urban poor.

Methods Data was collected via focus group discussions and key informant interviews in Freetown. Men and women with at least one child below the age of five under their care were included. Participants were selected from neighbourhoods in Freetown where Ola During Children's Hospital (ODCH) represented the nearest secondary care facility to their usual place of residence. Focus groups were facilitated in Krio, the national language, guided by a predesigned survey tool. Discussions were audio-recoded, transcribed and translated into English. Data analysis was conducted by the research team using a thematic framework.

Results Preliminary analysis reveals several factors contributing to delays in accessing appropriate care for sick children:

Indirect costs: Transportation, child-minding, lost income, cost of prescribed medicines and unsanctioned charges for care that continue to be levied.

The negative perceptions of ODCH staff and facilities: Perceived disrespectful, discriminatory or unfair treatment within the health facility.

Numerous healthcare options more easily accessible: Private pharmacies, self-treatment at home using traditional (herbal) or allopathic remedies.
Poor insight into disease: Deficiencies in caregivers' ability to recognise at what time during illness progression seeking healthcare would result in the highest cost benefit ratio.

Non caregiver factors: Long queues, perceived complicated referral process between FHC facilities, and reduced opening hours.

Conclusion User fees represent a major barrier to accessing timely and appropriate care for poor children. However, the elimination of official charges for paediatric care in Sierra Leone has brought to the surface several critical factors, beyond direct costs, which also impact upon healthcare utilisation. Understanding the processes and determinants which modulate health seeking behaviour is fundamental to efforts to improve health outcomes for the most vulnerable children.

\section{PS34 RECORDING AND MANAGEMENT OF OBESITY IN PRIMARY CARE, 1997-2006}

doi:10.1136/jech-2012-201753.133

HP Booth, M Gulliford. Department of Primary Care and Public Health Sciences, King's College London, London, UK

Background Primary care services play a potentially important role in the diagnosis and management of obesity but little evidence exists on current routine practice. The aim of this study was to describe the recording of body mass index and interventions used in the management of body weight in UK primary care in different categories of body weight.

Methods A retrospective cohort study was implemented using the UK General Practice Research Database (GPRD). Participants were aged between 18 and 100 and had a diagnosis of obesity and/or a record indicating a weight management intervention between 1997 and 2006. Diagnoses of obesity were identified by a medical code for obesity or a body mass index (BMI) record of $\geq 30 \mathrm{~kg} / \mathrm{m}^{2}$.Interventions were identified by medical and therapy codes and included advice on diet, body weight control or exercise, referral to specialist care for obesity or prescription of anti-obesity drugs.

Results Patients $(n=69,102)$ with a diagnosis of obesity or who received a weight management intervention were identified at 128 UK general practices. Average BMI rose slightly over the study period from $35.0 \mathrm{~kg} / \mathrm{m}^{2}$ in 1997 to $35.8 \mathrm{~kg} / \mathrm{m}^{2}$ in 2006, with a higher proportion of patients gaining rather than losing or maintaining their weight each year. Monitoring of BMI was infrequent with just $48 \%$ of patients previously identified as obese having a BMI recorded in 2006. The proportion of patients with one or more interventions for weight control recorded increased from 29\% in 1997 to $37 \%$ in 2006. The most frequent intervention throughout the study period was the provision of dietary advice, recorded in 13,097 (40.7\%) patients in 2006 compared to 3,401 (32.3\%) in 1997. Prescription of anti-obesity drugs increased by almost 60 -fold over the study period. The proportion of morbidly obese patients (BMI $\left.\geq 40 \mathrm{~kg} / \mathrm{m}^{2}\right)$ receiving a weight control intervention in 1997 was $38 \%$, rising to $63 \%$ in 2006 . In obesity category I (BMI $30-34.9 \mathrm{~kg} / \mathrm{m}^{2}$ ) the proportion receiving treatment was $43 \%$ in 1997 and $53 \%$ in 2006 and in category II (BMI $\left.35-39.9 \mathrm{~kg} / \mathrm{m}^{2}\right) 41 \%$ and $56 \%$ respectively.

Conclusion Monitoring of obesity in diagnosed patients was inconsistent in this population with less than half having a BMI recorded in each year of the study. The frequency of interventions for weight management increased substantially in primary care between 1997 and 2006.

\section{PS35 THE ROLE OF TIME PREFERENCE IN SMOKING CESSATION: A LONGITUDINAL ANALYSIS OF DATA FROM THE HOUSEHOLD INCOME AND LABOUR DYNAMICS OF AUSTRALIA SURVEY, 2001-08}

doi:10.1136/jech-2012-201753.134

J Adams, H Brown. Institute of Health \& Society, Newcastle University, Newcastle, UK 